\title{
Preparation and characterization of azithromycin nanodrug using solvent/antisolvent method
}

\author{
Hamid Reza Pouretedal
}

Received: 12 August 2013/Accepted: 18 February 2014/Published online: 15 March 2014

(C) The Author(s) 2014. This article is published with open access at Springerlink.com

\begin{abstract}
Nanoparticles of azithromycin are prepared using solvent/antisolvent precipitation method. The solubility of drug in water and the oral bioavailability are increased with decreasing particle size. The effect of type and concentration of surfactant and feed drug concentration are evaluated on the precipitated particle size. The nanoazithromycin in range $200-400 \mathrm{~nm}$ is obtained by the addition of absolute ethanol as solvent, water as antisolvent in presence of Tween ${ }^{\circledR} 80$ as surfactant. The prepared nanoparticles are characterized by infra-red spectra, particle size distribution, scanning electron microscopy, X-ray diffraction and differential scanning calorimetry. The chemical structure of nanosized azithromycin does not show any change but the crystallinity reduces in comparison with raw drug. Dissolution of azithromycin nanoparticles in purified water and buffer phosphate ( $\mathrm{pH}$ of 6.0$)$ is 2.93 and 3.36, respectively, times of raw drug in $30 \mathrm{~min}$.
\end{abstract}

Keywords Azithromycin - Nanoparticles · Antisolvent · Bioavailability $\cdot$ Tween ${ }^{\circledR} 80$

\section{Introduction}

In the manufacture of pharmaceutical compounds, crystallization is a critical unit operation. So, it is often a key isolation step or a purification process in the synthesis of an active pharmaceutical ingredient (API). Crystallization of an API sometime is critical for product qualities such as chemical purity and correct polymorphic form, which need

H. R. Pouretedal $(\bowtie)$

Faculty of Applied Chemistry, Malek-ashtar University

of Technology, Shahin-Shahr, Iran

e-mail: HR_POURETEDAL@mut-es.ac.ir to be strictly controlled to meet set specifications [1]. Optimization of the crystallization process for an API is important not only for the key product requirements mentioned above but also for process efficiency. The API crystallization process shows a significant effect on downstream processing. For example, excess fines or wide particle size distribution may cause slow filtration and inefficient drying, which may be a major bottleneck of the entire manufacturing process. It is often necessary to modify the crystallization process to control particle properties to facilitate downstream operations [2]. Thus, to control the particle size and particle size distribution (PSD) and to improve the stability, it is necessary to increase the nucleation rate, inhibit the particle growth, and control the agglomeration of particles by steric or electrostatic stabilization [3-6]. Two main steps in the process of particle formation are the mixing of the solution and antisolvent streams to generate supersaturation and the precipitation of the particles, leading to two main time scales, the mixing time and the precipitation or induction time [7-9].

If the supersaturation attained is high and is realized over a very short period of time, then the metastable region is crossed quickly, the process of nucleation dominates the crystallization process [10] and a large number of nuclei are formed, resulting in the precipitation of ultrafine particles. Physical properties such as particle size, crystal habit, and surface properties are important aspects of API product quality and must be considered with great care and attention during the development of an API crystallization process [11]. The effort of modifying a crystallization process to effect changes in the physical properties of crystals is often called particle engineering [12]. For insoluble or dissolution-limited drug substances, small particle size is necessary to maximize surface area to enhance bioavailability [13]. According to Noyes-Whitney 
equation, the dissolution rate is proportional to the surface area exposed to the dissolution medium [14]. The crystallization process is a very important stage in production of active pharmaceutical ingredients. There are many different crystallization methods including cooling crystallization-based method [15, 16], supercritical fluid-based methods [17-19], precipitation-based methods [20-22], and microemulsion techniques [23, 24] and cooling crystallization is a commonly used method that often requires heating the system to higher temperatures to dissolve all the crystals. However, as some pharmaceutical compounds are heat sensitive, elevated temperatures can lead to decomposition of the compound, resulting in failed batches. Antisolvent crystallization is usually used for heatsensitive compounds and for compounds in which there are insignificant changes in solubility with temperature [25]. This method requires adding a poor solvent (antisolvent) to the solution in which the solute is dissolved in, forming a supersaturated solution that results in the crystallization of the compound in nanosized form [26, 27]. Many new drugs are poorly water soluble and their dissolution rates can be improved by decreasing particle size [28]. Decreasing the size increases the surface area, which results in an increase in the rate of dissolution of these drugs in aqueous media such as body fluids [29]. Azithromycin is absorbed rapidly after oral administration with a bioavailability of about $36 \%$. It has a variable effect with food. It is also as a poorly water-soluble drug. To obtain a good solubility for azithromycin, we must decrease its particle size.

In recent years, an area that is gaining popularity with formulation scientists for developing a viable dosage form for poorly soluble compounds that are moderately potent is to develop a formulation incorporating drug nanoparticles, usually $<1 \mu \mathrm{m}$ in diameter. For example, when the particle size of the drug is reduced from $8 \mu \mathrm{m}$ to $200 \mathrm{~nm}$ there is a 40 -fold increase in the surface area to volume ratio [20-24].

\section{Materials and methods}

\section{Materials}

The used chemicals were with analytical grade and highest purity. Azithromycin (Fig. 1) dehydrate (SANDOZ Pharmaceutical Co., PVP K30, Povidone K30, BASF Germany), hydroxypropyl methyl cellulose (ALDRICH 42,321-1, HPMC), polyvinyl acetate (ALDRICH 38,793-2, PVAc), methyl cellulose (ALDRICH 18,804-2, MC), hydroxypropyl methyl cellulose phthalate (ALDRICH 43,520-1, HPMC-P), ethanol absolute GR for analysis, polyvinyl alcohol 72000 for synthesis (PVA), sodium lauryl sulfate (Ph. Eur., SLS), Tween ${ }^{\circledR} 80$ (Ph. Eur. JP, NF, polysorbate), triton ${ }^{\circledR} \mathrm{X}-100 \mathrm{GR}$, polyethylene glycol 400

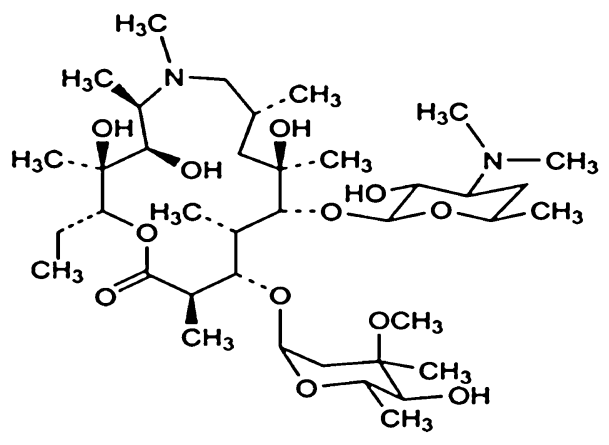

Fig. 1 Azithromycin structure

for synthesis (PEG 400) were used in this work. The Purified water was used to prepare aqueous solutions and was obtained by a suitable process. It was prepared from water complying with the US Environmental Protection Agency, with conductivity $<1.0 \mu \mathrm{s} / \mathrm{cm}$ Pharm. USP.

Preparation of azithromycin nanoparticles

Azithromycin nanoparticles were produced by antisolvent precipitation method. The ethanol absolute was used as water miscible solvent. The supersaturation solution $(0.556 \mathrm{~g} / \mathrm{ml})$ of azithromycin in ethanol was then filtrated through a $0.4 \mu \mathrm{m}$ nylon filter membrane to remove solid impurities to obtain a clear azithromycin solution. The obtained drug solution was then injected with a rate of $100 \mu \mathrm{l} / \mathrm{s}$ into the water containing the Tween ${ }^{\circledR} 80$ stabilizer $(4.5 \mathrm{mg} / \mathrm{ml})$ under stirring at 2,500 rpm. Precipitation of solid drug particles was formed immediately upon mixing at ambient temperature. The obtained suspension was centrifuged at 15,300 rpm for $30 \mathrm{~min}$ and the removed nanoparticles were washed twice with purified water to remove both the ethanol and Tween ${ }^{\circledR}$ 80. The effect of other stabilizers such as HPMC, HPMC-P, SLS, PVA, MC, PVAc, Triton ${ }^{\circledR} \mathrm{X}-100$, PVP K30 and PEG 400 on the distribution of nanoparticles size of azithromycin was also studied.

\section{Water content test}

Many pharmaceutical compounds either are hydrates or contain water in adsorbed form. As a result, determination of the water content is important in demonstrating compliance with the pharmaceutical standards. A sample $(500 \mathrm{mg})$ was used as water determent sample. It was titrated with Karl Fischer pyridine free reagent (according to USP 34, method I $\langle 921\rangle$ ).

Particle size measurement

After the preparation of azithromycin nanoparticles by antisolvent precipitation method, size of the prepared drug 
particles was measured immediately after precipitation by dynamic laser light scattering (Nano-particle size analyzer, Malvern). Before this measurement, the drug suspension was diluted by purified water to $0.2 \mathrm{mg} / \mathrm{ml}$.

IR spectra

Shimadzu IR-470 spectrometer was used to record the IR spectrum of the drugs from 400 to $4,000 \mathrm{~cm}^{-1}$. The samples were diluted with $\mathrm{KBr}$ mixing powder at $1 \%(\mathrm{w} / \mathrm{w})$ and pressed to obtain self-supporting disks.

DSC analysis

Differential scanning calorimetry (DSC) was conducted on DSC 131 SETARAM. The samples were equilibrated at $20{ }^{\circ} \mathrm{C}$ for $30 \mathrm{~min}$. Indium standard was used to calibrate the DSC temperature and enthalpy scale. The samples $(0.1 \mathrm{~g})$ in hermetically sealed aluminum pans were heated at a temperature range of $20-500{ }^{\circ} \mathrm{C}$ at $3{ }^{\circ} \mathrm{C} / \mathrm{min}$. Inert atmosphere was maintained by purging nitrogen at the flow rate of $15.8 \mathrm{ml} / \mathrm{min}$, linear velocity $35 \mathrm{~cm} / \mathrm{s}$ and pressure $24.6 \mathrm{kPa}$.

\section{Scanning electron microscopy (SEM)}

The surface morphologies of the nanosized azithromycin were observed by scanning electron microscopy (SEMAIS-2100) with an accelerating voltage of approximate $1.5-20 \mathrm{kV}$. Gold coating was performed to prevent chargeup of sample for $35 \mathrm{~s}$.

\section{Dissolution rate test}

Dissolution rate tests were carried out by the USP 34 method, apparatus type I (Basket) (Pharma test, as a dissolution tester). The basket speed and bath temperature were set at $100 \mathrm{rpm}$ and $37.0 \pm 0.5{ }^{\circ} \mathrm{C}$, respectively. A $250 \mathrm{mg}$ of azithromycin reference standard and nanosized azithromycin powder were, respectively, added into different vessels containing $900 \mathrm{ml}$ of purified water. This test was repeated with phosphate buffer $(\mathrm{pH}=6.0)$ and compared obtained results with purified water drug solubility. In the intervals of 5, 10, 20, 30, 60, $120 \mathrm{~min}, 2.0 \mathrm{ml}$ aliquot samples was taken and transferred to a $25-\mathrm{ml}$ volumetric flask and then diluted with mobile phase to volume and filtered through $0.45 \mu \mathrm{m}$ syringe filter. Then, $4.0 \mathrm{ml}$ of this solution was transferred to a second 25-ml volumetric flask and diluted with mobile phase to volume. The concentration of the samples was assayed by a HPLC system (Waters-Alliance 2690, USA) at $210 \mathrm{~nm}$ (USP 34).
Nano-azithromycin purity test (assay)

The solution A was a mixture 60:40 of acetonitrile:dipotassium hydrogen phosphate $(6.7 \mathrm{~g} / \mathrm{l}$ and $\mathrm{pH}$ 8.0). To prepare test solution, $53.0 \mathrm{mg}$ of the substance was dissolved in $2 \mathrm{ml}$ of acetonitrile and diluted to $100.0 \mathrm{ml}$ with solution A. Reference solution was prepared by dissolving $53.0 \mathrm{mg}$ of standard azithromycin in $2 \mathrm{ml}$ of acetonitrile and diluted to $100.0 \mathrm{ml}$ with solution A.

The system requirements of test are as follows, flow rate of $1.0 \mathrm{ml} / \mathrm{min}$, column size $4.6 \mathrm{~mm} \times 25 \mathrm{~cm}, 5 \mu \mathrm{m}$ octadecylsilyl vinyl polymer, column temperature $40{ }^{\circ} \mathrm{C}$, detection system of spectrophotometer at $210 \mathrm{~nm}$, injection volume of $10 \mu \mathrm{l}$ and run time of 1.5 times the retention time of azithromycin. For analysis of impurity substances, a mixture solvent of ammonium dihydrogen phosphate $(\mathrm{pH}=10)$ :acetonitrile:methanol with ratio 3.5:3.0:3.5 was prepared. To prepare a test solution, $0.200 \mathrm{~g}$ of the nano-azithromycin was dissolved in $25.0 \mathrm{ml}$ of the solvent mixture. The conditions of analysis are as follows: $4.6 \mathrm{~mm} \times 25 \mathrm{~cm}$ column, temperature $60{ }^{\circ} \mathrm{C}$, mobile phase $\mathrm{A} ; 1.80 \mathrm{~g} / \mathrm{l}$ solution of buffer phosphate adjusted to $\mathrm{pH} 8.9$, mobile phase $\mathrm{B}$; methanol:acetonitrile $(250: 750 \mathrm{~V} / \mathrm{V})$, flow rate $1.0 \mathrm{ml} / \mathrm{min}$, detection spectrophotometer at $210 \mathrm{~nm}$ and injection volume $50 \mu \mathrm{l}$. Acceptance criteria's for this analysis is as follows: impurity $\mathrm{B}$ must be $<2.0 \%$; impurities $\mathrm{A}, \mathrm{C}, \mathrm{E}$, F, G, H, I, L, M, N, O, P must be $<0.5 \%$; sum of impurities D and $\mathrm{J}$ must be $<0.5 \%$; any other impurities for each impurity must be $<0.2 \%$ and total impurities must be $<3.0 \%$. All obtained results are cited in Table 5.

\section{Stability test}

According to ICH and WHO guidelines "Stability testing of new drug substances and products" [Q1A (R2)] and "Impurities in new drug substances" [Q3A (R2)] and stability conditions for WHO member states by region, Iran is in zone III a hot and dry place. For samples stored at room temperature, we must place nano-azithromycin in a relevant tight container at $30 \pm 2{ }^{\circ} \mathrm{C}$ and $\mathrm{RH}$ (Relative Humidity) of $65 \pm 5 \%$ for 12 months [7, 30]. At this work, we use RU MED-Germany stability chamber. About $100 \mathrm{~g}$ of nanosized sample was placed in a relevant tight container and then monitored at $30{ }^{\circ} \mathrm{C}$ and $65 \%$ of $\mathrm{RH}$ for long-term analysis (12 month). According to the WHO guideline, the stability results are failing if the significant change is a $5 \%$ or more in the assay from its initial content of API. 


\section{Results and discussion}

\section{Effect of stabilizer}

Azithromycin nanoparticles were prepared by the solventantisolvent precipitation method. The injection of the drug solution to the antisolvent of water generates high supersaturation. At these conditions, the nucleation rate is fast and produces a large number of nuclei, which reduces the solute mass for subsequent growth. Nanoparticles are formed while the growth of nucleating crystals is arrested by the stabilizer (surfactant or polymer) through steric or electrostatic mechanism [31]. For many hydrophobic drugs, water is commonly used as the antisolvent. In terms of the solvent, it is beneficial if it can solubilize the drug in large amount and possesses a fast diffusion rate in antisolvent of water. While the stabilizer needs to have good

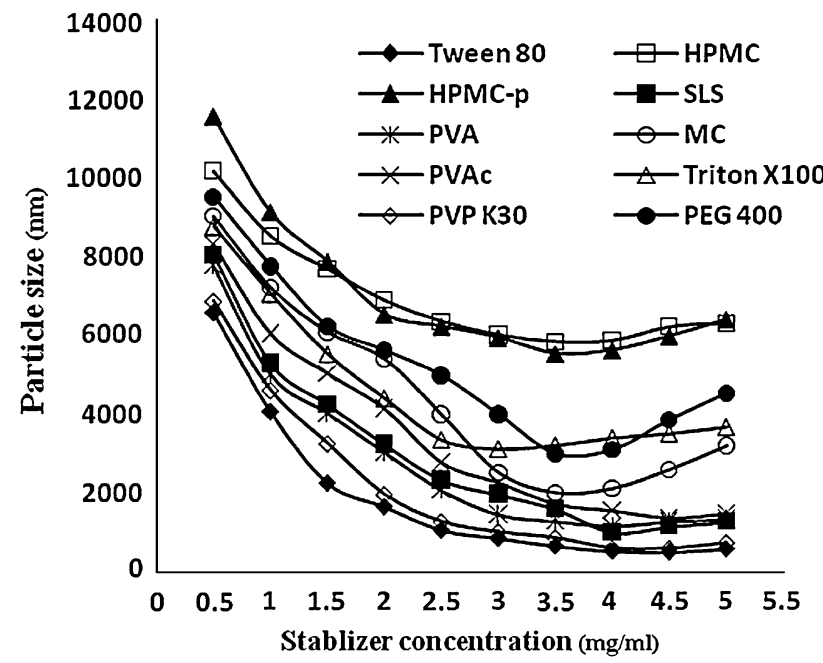

Fig. 2 Influence of type and concentration of stabilizer on particle size distribution affinity for drug particles and possess a fast diffusion rate and effective adsorption onto the drug particles surface in solvent/antisolvent mixture. Therefore, solvent-stabilizer pair is crucial to obtain nanoparticles. Preparation of drug nanoparticles usually requires a careful selection of stabilizers. In our experiments, ten stabilizers including HPMC, HPMC-P, SLS, Tween ${ }^{\circledR}$ 80, PVA, MC, PVAc, Triton ${ }^{\circledR}$ X-100, PVP K30 and PEG 400 were evaluated. The effects of stabilizers at a concentration range of $0.5-5.0 \% \mathrm{w} / \mathrm{v}$ are studied on precipitated azithromycin particles size and particles size distribution. The obtained results are shown in Fig. 2 and sited in Table 1. As seen, in the presence of Tween $^{\circledR} 80$ as stabilizer, the distribution of nanoparticles size is obtained at a range of 200-450 nm (Fig. 3).

\section{Characterization of nano-azithromycin}

Raw azithromycin and precipitated nanoparticles with principal peaks at wavenumbers 1721,1188 and $1052 \mathrm{~cm}^{-1}$ exhibits same IR spectrum as shown in Fig. 4, which demonstrates that the chemical structure of the drug does not change with decreasing of particles size in solvent/ antisolvent method.

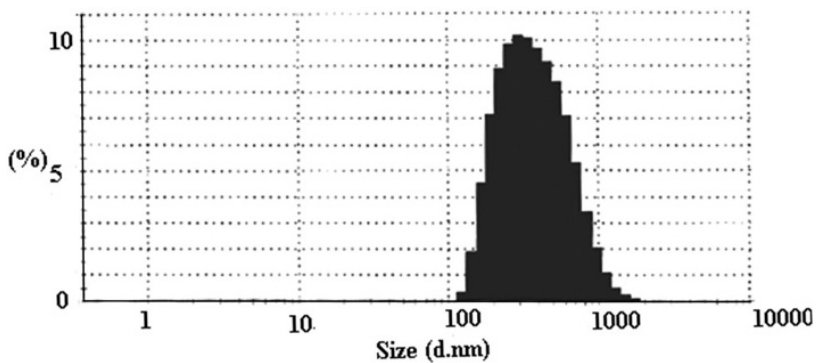

Fig. 3 Nano-azithromycin particle size distribution in $4.5 \mathrm{mg} / \mathrm{ml}$ tween 80 concentration
Table 1 Influence of type and concentration of stabilizer on particle size distribution

\begin{tabular}{lrlllllllll}
\hline $\begin{array}{l}\text { Concentration } \\
(\mathrm{mg} / \mathrm{ml})\end{array}$ & \multicolumn{1}{l}{ Particle size distribution (PSD) (nm) } \\
\cline { 2 - 12 } & HPMC & $\begin{array}{l}\text { HPMC- } \\
\text { P }\end{array}$ & SLS & PVA & PVAc & $\begin{array}{l}\text { PVP } \\
\text { K30 }\end{array}$ & $\begin{array}{l}\text { Triton }^{\circledR} \\
\text { X100 }\end{array}$ & $\begin{array}{l}\text { Tween } \\
80\end{array}$ & MC & $\begin{array}{l}\text { PEG } \\
400\end{array}$ \\
\hline 0.5 & 10,162 & 11,521 & 8,021 & 7,758 & 8,305 & 6,860 & 8,752 & 6,566 & 9,011 & 9,500 \\
1.0 & 8,526 & 9,105 & 5,281 & 5,008 & 6,045 & 4,602 & 7,056 & 4,060 & 7,210 & 7,758 \\
1.5 & 7,690 & 7,856 & 4,240 & 4,027 & 5,036 & 3,250 & 5,525 & 2,252 & 6,088 & 6,230 \\
2.0 & 6,895 & 6,522 & 3,225 & 3,030 & 4,138 & 1,952 & 4,410 & 1,651 & 5,400 & 5,621 \\
2.5 & 6,365 & 6,220 & 2,324 & 2,060 & 2,769 & 1,265 & 3,358 & 1,058 & 3,984 & 4,989 \\
3.0 & 6,023 & 5,935 & 1,955 & 1,445 & 2,260 & 1,005 & 3,126 & 856 & 2,511 & 4,002 \\
3.5 & 5,852 & 5,528 & 1,590 & 1,273 & 1,722 & 855 & 3,222 & 657 & 2,005 & 3,012 \\
4.0 & 5,885 & 5,621 & 1,002 & 1,159 & 1,550 & 589 & 3,410 & 525 & 2,115 & 3,121 \\
4.5 & 6,231 & 5,978 & 1,152 & 1,265 & 1,368 & 586 & 3,518 & 504 & 2,599 & 3,882 \\
5.0 & 6,322 & 6,399 & 1,263 & 1,328 & 1,471 & 729 & 3,688 & 586 & 3,200 & 4,550 \\
\hline
\end{tabular}


The physical state of raw azithromycin and drug nanoparticles is examined by DSC and their thermograms are shown in Fig. 5. Raw azithromycin exhibits a melting point at $114.760 \pm 0.095^{\circ} \mathrm{C}$, with fusion enthalpy of $68.496 \pm 0.088 \mathrm{~J} / \mathrm{g}$. The melting point and fusion enthalpy of prepared nanoparticles were $100.238 \pm 0.085{ }^{\circ} \mathrm{C}$ and $35.126 \pm 0.150 \mathrm{~J} / \mathrm{g}$, respectively. The decrease in thermal properties shows the decrease in crystallinity in nanoparticles. The DSC analysis of raw and nanoparticles in 3 days shows the reproducibility of the results (Table 2).

The stability test shows that the prepared nanosuspension is stable for at least $6 \mathrm{~h}$. The SEM image and the particle size distribution of the azithromycin nanoparticles, were obtained from freshly formed nanosuspension, are shown in Fig. 6a. The morphology of azithromycin

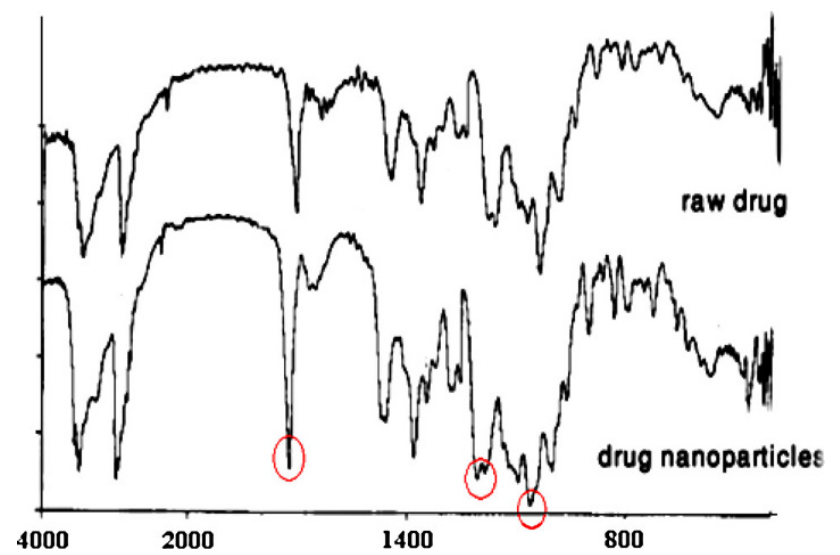

Fig. 4 IR spectra of raw drug and nano-azithromycin nanoparticles was compared with raw drug optical microscopic view in $400 \times$ zoom in Fig. 6b. The morphology of raw drug and nanoparticles is the same. SEM image shows that the size of the nanoparticles is in the range 200-450 nm (Fig. 6c).

The sample X-ray diffraction pattern in Fig. 7 shows that the main peak is occurred in $2 \theta$ about $10^{\circ}$ and other important peaks appear at $2 \theta$ about $6,9.5,12,15.5,16.5$, 17.5 and $18.8^{\circ}$. The obtained XRD pattern is same with XRD pattern of azithromycin dehydrate in the European Patent application EPO 984020A2 [32].

The mass spectra of nano-azithromycin are shown in Fig. 8, which are same with that of raw azithromycin [33]. The mass peaks with $\mathrm{M} / \mathrm{z}$ of $374.1,375,749,750$ and 751 reconfirm the molecular structure of nanosized azithromycin.

Table 2 DSC results of standard azithromycin and nano-azithromycin in 3 days

\begin{tabular}{lclll}
\hline No. & $\begin{array}{l}\text { Reference } \\
\text { melting } \\
\text { point }\left({ }^{\circ} \mathrm{C}\right)\end{array}$ & $\begin{array}{l}\text { Reference } \\
\text { enthalpy } \\
(\mathrm{J} / \mathrm{g})\end{array}$ & $\begin{array}{l}\text { Nano- } \\
\text { azithromycin } \\
\text { melting point } \\
\left({ }^{\circ} \mathrm{C}\right)\end{array}$ & $\begin{array}{l}\text { Nano- } \\
\text { azithromycin } \\
\text { enthalpy }(\mathrm{J} / \mathrm{g})\end{array}$ \\
\hline 1 & 114.868 & 68.554 & 100.283 & 35.074 \\
2 & 114.611 & 68.413 & 100.314 & 35.199 \\
3 & 114.802 & 68.522 & 100.119 & 35.107 \\
Average & 114.760 & 68.496 & 100.239 & 35.127 \\
SD & 0.109 & 0.061 & 0.086 & 0.053 \\
RSD & 0.095 & 0.088 & 0.085 & 0.151 \\
$(\%)$ & & & & \\
\hline
\end{tabular}

Fig. 5 DSC spectrum of a raw drug and $\mathbf{b}$ nano-azithromycin

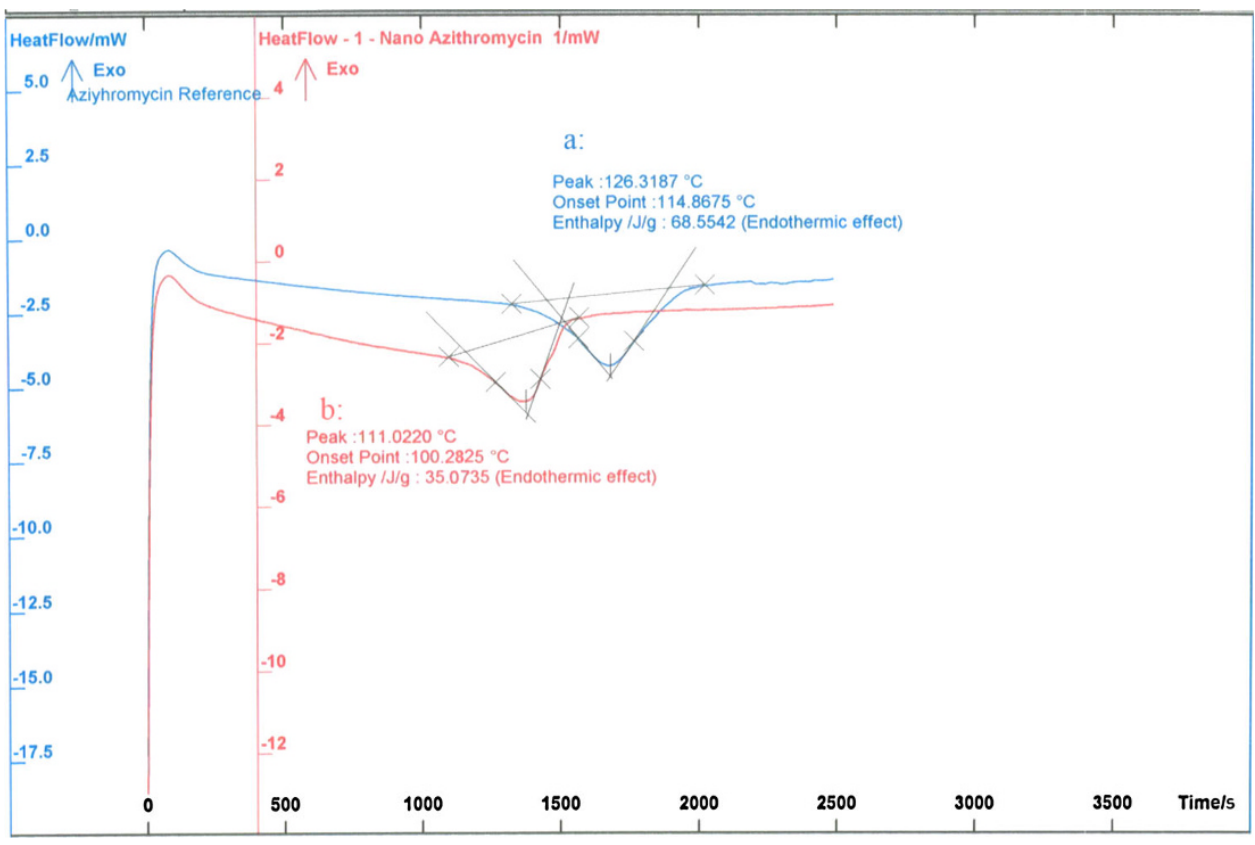



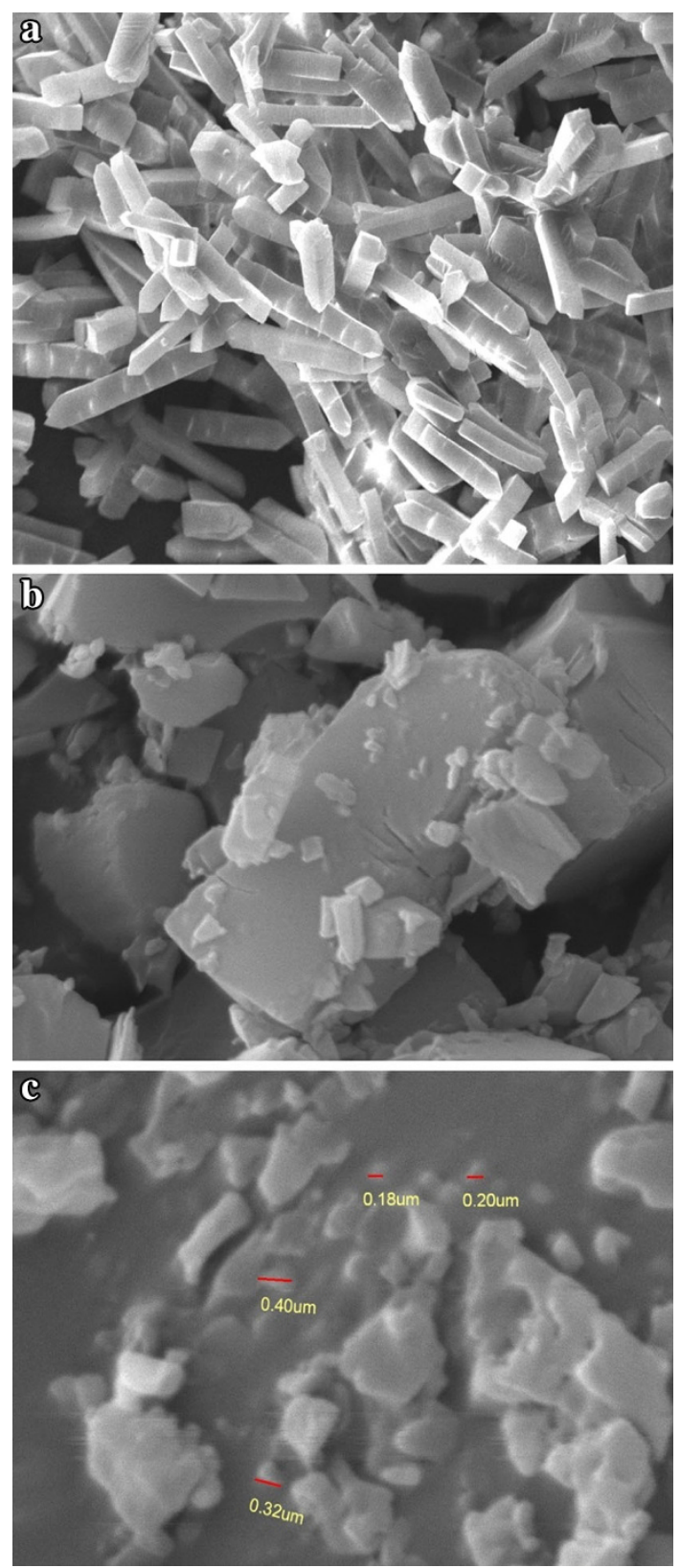

Fig. 6 SEM images of a raw drug and nano-azithromycin with magnification of $\mathbf{b} 10,000$ and $\mathbf{c} 30,000$

\section{Assay}

Azithromycin is in three crystallization forms, anhydrous form with water content $<2.0 \%$, monohydrate with water content between 2.0 and $4.0 \%$ and dihydrate form with exact water content $4.0-5.0 \%$. The prepared nanoparticles show $4.614 \pm 0.025 \%$ of water and thus it is a dihydrate form of azithromycin.

The purity of precipitated nanoparticles was calculated from British Pharmacopoeia (BP 2010) sixth edition and show that the precipitated nanoparticles are of highest purity. Obtained HPLC spectra for standard azithromycin and precipitated nano-azithromycin show the retention time of $6.2 \mathrm{~min}$. Analysis of azithromycin nanoparticles shows that the individual related substances are $<0.1 \%$ and its total impurities are $<0.3 \%$ (BP 2010). Thus, the obtained purity of precipitated nanoparticles was $99.58 \pm 0.73 \%$. All the results from this calculation are sited in Table 3.

Azithromycin, as a kind of hydrophobic drug, has a low bioavailability of about $37 \%$ due to its low dissolution rate. Dissolution profiles of raw azithromycin and precipitated nanoparticles at room temperature are illustrated in Fig. 9. The dissolution rate of azithromycin nanoparticles is $3.36 \pm 0.01$ times that of raw drugs (Table 4). According to Noyes-Whitney equation [34], the solid dissolution rate is directly proportional to its surface area exposed to the dissolution medium. The accelerated dissolution for azithromycin nanoparticles is mainly ascribed to their greater surface area in comparison with raw drug. The dissolution results in purified water and in buffer phosphate of pH 6.0 are 2.93 and 3.36 times, respectively, faster than raw drug in first $30 \mathrm{~min}$. After that, the dissolution has no significant difference from raw drug.

The precipitated nanoparticles after its initial tests as mentioned above are placed in a relevant tight container for 12 months in RU MED chamber at a temperature of $30^{\circ} \mathrm{C}$ and $\mathrm{RH}$ of $65 \%$. The powder appearance and physical attributes, assay, impurities, $\mathrm{pH}$ and water content are checked periodically. This analysis was repeated three times for each test. The obtained results are sited in Table 5. The obtained results show that there is no significant change on appearance and physical attributes, also the assay and impurity results show the maximum $3.4 \%$ decrease in the assay from initial potency. Moreover, obtained results indicate the impurity $\mathrm{B}$ is $<1.1 \%$; impurities $\mathrm{A}, \mathrm{C}, \mathrm{E}, \mathrm{F}, \mathrm{G}, \mathrm{H}, \mathrm{I}, \mathrm{L}, \mathrm{M}, \mathrm{N}, \mathrm{O}, \mathrm{P}<0.2 \%$; sum of impurities $\mathrm{D}$ and $\mathrm{J}$ are $<0.3 \%$; any other impurities for each impurity are $<0.2 \%$ and total impurities are $<1.8 \%$. However, increasing impurities during stability conditions is due to the increase of $\mathrm{pH}$ to 10.7 and water content to $4.8 \%$. The stability results show that the precipitated nanoazithromycin powder is a stable active pharmaceutical ingredient.

\section{Conclusion}

The solvent/antisolvent precipitation method can be used to prepare of azithromycin nanoparticles. The ethanol solvent used to prepare supersaturation solution of drug and Tween ${ }^{\circledR} 80$ as a stabilizer used to control of particle size distribution of nanodrug. Azithromycin nanoparticles show dissolution rate in water as 3.36 times of raw drug. The 
Fig. 7 XRD pattern of nanoazithromycin

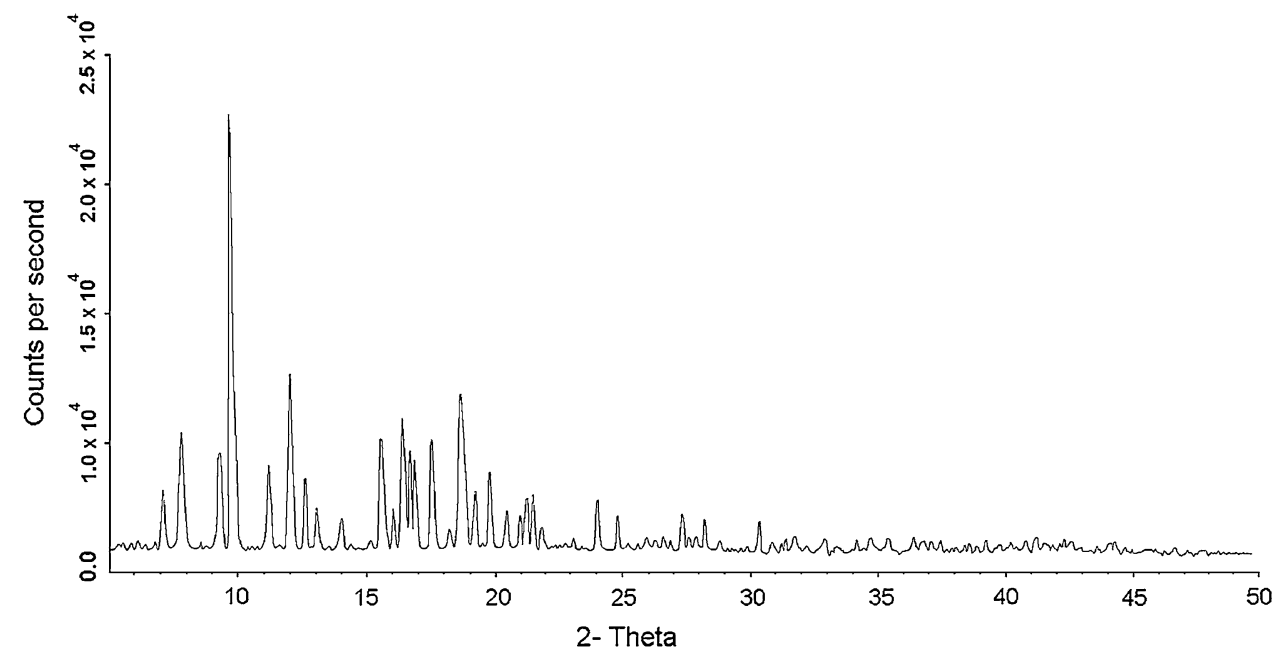

Fig. 8 Mass spectra of nanoazithromycin

Table 3 Assay results obtained from HPLC analysis according to USP 34 , Standard area is 49,540

\begin{tabular}{lc}
\hline Sample area & Assay $(\% \mathrm{w} / \mathrm{w})$ \\
\hline 50,644 & 99.98 \\
50,994 & 100.67 \\
50,123 & 98.95 \\
50,205 & 99.11 \\
50,244 & 99.19 \\
Average & 99.58 \\
SD & 7.27 \\
RSD (\%) & 0.73 \\
\hline
\end{tabular}

lack of variation in structure and purity of nanodrug are confirmed by similarity in IR spectra, XRD pattern, MS spectra and retention time in HPLC of raw and
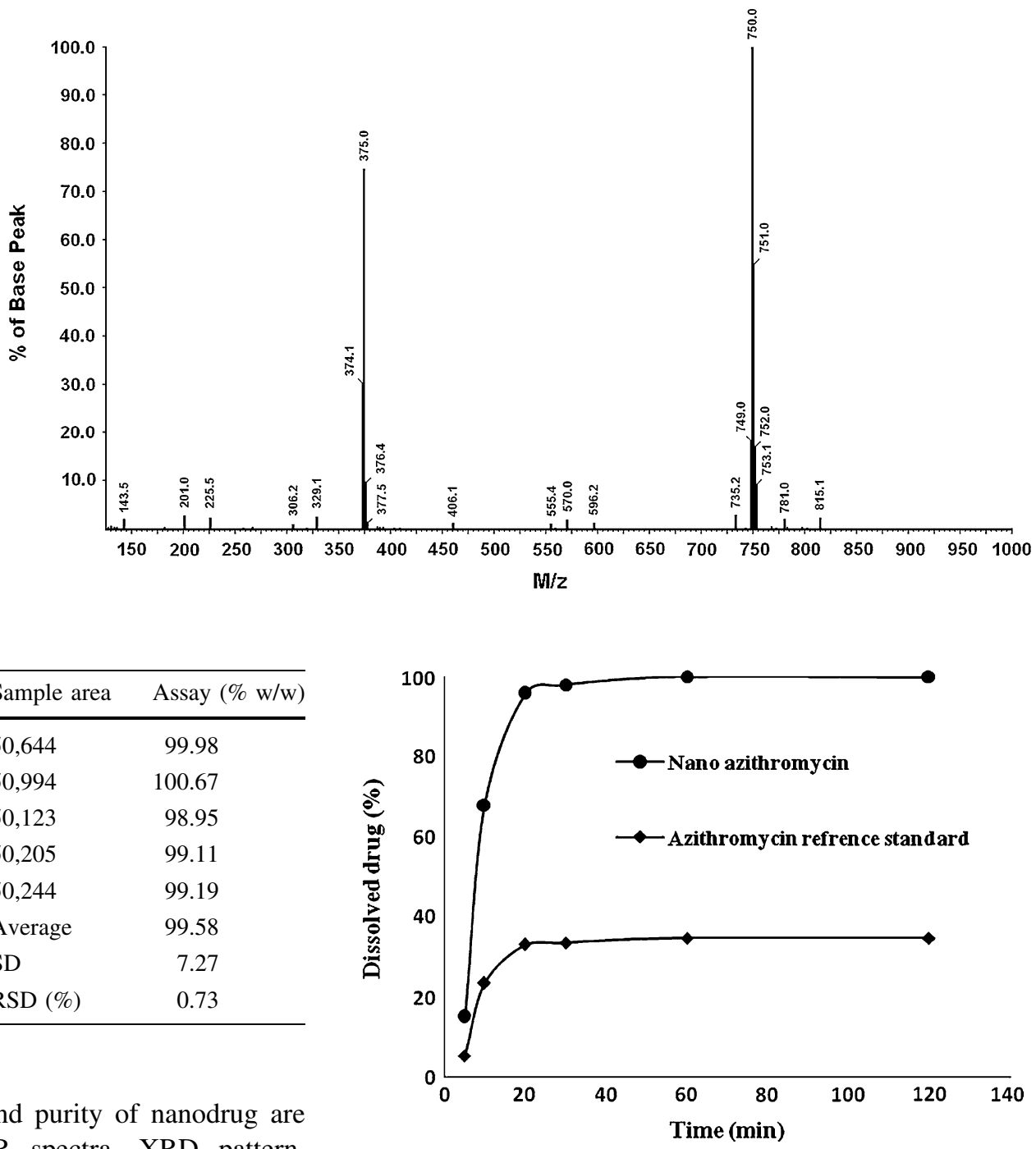

Fig. 9 Dissolution profile of raw drug and nano-azithromycin 
Table 4 The results of dissolution test of raw and nanoazithromycin in purified water and GI solution

\begin{tabular}{llllllll}
\hline $\begin{array}{l}\text { Raw } \\
\text { azithromycin in } \\
\begin{array}{l}\text { purified water } \\
(\%)\end{array}\end{array}$ & $\begin{array}{l}\text { RSD } \\
(\%)\end{array}$ & $\begin{array}{l}\text { Nano- } \\
\text { azithromycin in } \\
\text { purified water } \\
(\%)\end{array}$ & $\begin{array}{l}\text { RSD } \\
(\%)\end{array}$ & $\begin{array}{l}\text { Raw } \\
\text { azithromycin in } \\
\text { GI solution (\%) }\end{array}$ & $\begin{array}{l}\text { RSD } \\
(\%)\end{array}$ & $\begin{array}{l}\text { Nano- } \\
\text { azithromycin in } \\
\text { GI solution (\%) }\end{array}$ & $\begin{array}{l}\text { RSD } \\
(\%)\end{array}$ \\
\hline 10.0 & 0.82 & 15.0 & 1.12 & 11.5 & 0.69 & 27.8 & 1.01 \\
12.5 & 1.02 & 59.0 & 0.85 & 42.9 & 1.33 & 72.4 & 0.55 \\
19.8 & 0.61 & 76.6 & 0.88 & 70.2 & 1.02 & 91.0 & 0.95 \\
24.9 & 0.77 & 82.9 & 0.14 & 79.8 & 0.96 & 96.9 & 0.66 \\
29.3 & 0.23 & 87.5 & 0.29 & 83.3 & 0.20 & 99.4 & 0.04 \\
29.8 & 0.30 & 87.2 & 0.66 & 83.5 & 0.91 & 100.0 & 0.41 \\
\hline
\end{tabular}

GI Gastrointestinal

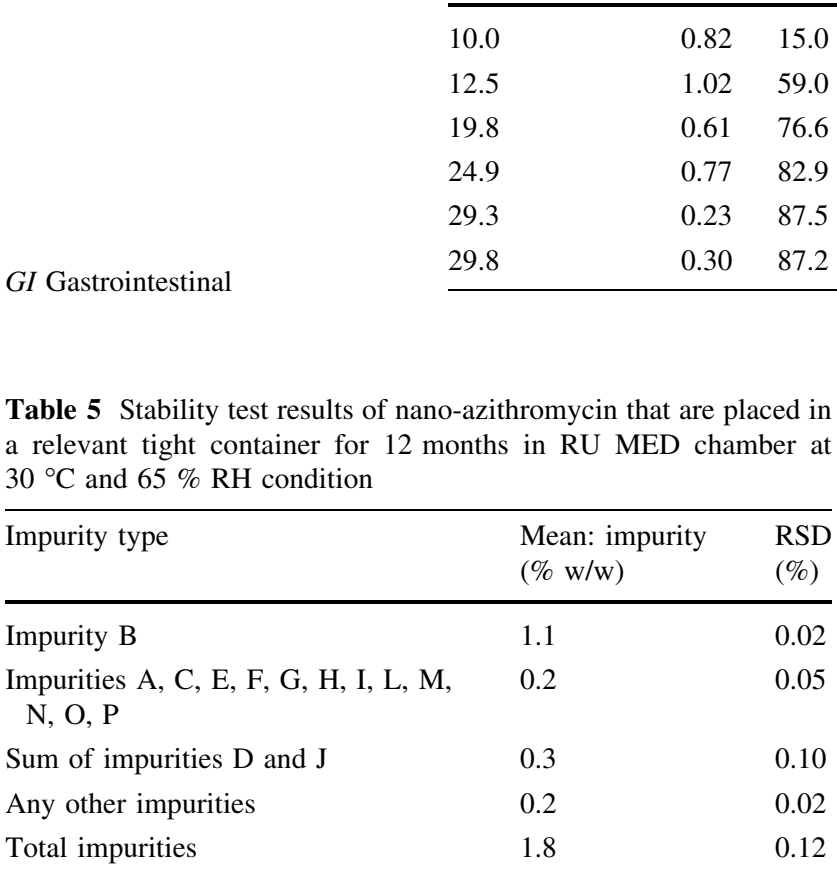

nano-azithromycin. The obtained particle size distribution shows that the precipitated nano-azithromycin has a particle size of about $200-450 \mathrm{~nm}$.

Acknowledgments I would like to thank the research committee of Islamic Azad University, Shahreza Branch and M. Sc. M. Mansori for supporting this work.

Open Access This article is distributed under the terms of the Creative Commons Attribution License which permits any use, distribution, and reproduction in any medium, provided the original author(s) and the source are credited.

\section{References}

1. Mullin, J.W.: Crystallization, 3rd edn, p. 421. Butterworth-Heinemann, Boston (1993)

2. Lipinski, C.A.: Poor aqueous solubility, an industry wide problem in drug discovery. Am Pharm ReV 53, 82-85 (2002)

3. Mersmann, A.: Crystallization and precipitation. Chem. Eng. Sci. 38, 345-353 (1999)

4. Dalvi, S.V., Dave, R.N.: Controlling particle size of a poorly water-soluble drug using ultrasound and stabilizers in antisolvent precipitation. Ind. Eng. Chem. Res. 48, 7581-7593 (2009)

5. Mosharrafand, M., Nystrom, C.: The effect of particle size and shape on the surface specific dissolution rate of microsized practically insoluble drugs. Int. J. Pharm. 122, 35-47 (1995)

6. Muller, R.H., Jacobs, C., Kayser, O.: Nanosuspensions as particulate drug formulations in therapy. Rationale for development and what we can expect for the future. Adv. Drug Delivery Rev. 47, 3-19 (2001)

7. Matteucci, M.E., Hotze, M.A., Johnston, K.P., Williams, R.O.: Drug nanoparticles by antisolvent precipitation: mixing energy versus surfactant stabilization. Langmuir 22, 8951-8959 (2006)

8. Gradl, J., Schwarzer, H., Schwertfirm, F., Manhart, M., Peukert, W.: Precipitation of nanoparticles in a T-mixer: coupling the particle population with hydrodynamics through direct numerical simulation. Chem. Eng. Process. 45, 908-916 (2006)

9. Johnson, B.K., Prud'homme, R.K.: Flash nanoprecipitation of organic actives and block copolymers using a confined impinging jets mixer. Aust. J. Chem. 56, 1021-1024 (2003)

10. Ventosa, N., Veciana, J., Sala, S., Munto, M., Cano, M., Gimeno, M.: New technologies for the preparation of micro- and nanostructured materials with potential applications in drug delivery and clinical diagnostics. Contrib. Sci. 3, 11-20 (2005)

11. Kim, S., Lotz, B., Lindrud, M., Girard, K., Moore, T., Nagarajan, K., Alvarez, M., Lee, T.: Control of the particle properties of a drug substance by crystallization engineering and the effect on drug product formulation. Org. Proc. Res. Dev. 9, 894-901 (2005)

12. Liversidge, G.G., Cundy, K.C.: Particle size reduction for improvement of oral bioavailability of hydrophobic drugs: absolute oral bioavailability of nanocrystalline Danzol in beagle dogs. Int. J. Pharm. 125, 91-97 (1995)

13. Noyes, A.A., Whitney, W.R.: The rate of solution of solid substances in their own solutions. J. Am. Chem. Soc. 19, 930-934 (1997)

14. Kesisoglou, F., Panmai, S., Wu, Y.: Nanosizing- oral formulation development and biopharmaceutical evaluation. Adv. Drug Deliv. Rev. 59, 631-644 (2007)

15. Mullin, J.W., Nyvlt, J.: Programmed cooling of batch crystallizers. Chem. Eng. Sci. 26, 369-377 (1971)

16. Gabas, N., Lague'rie, C.: Batch crystallization of D-xylose by programmed cooling or by programmed adding of ethanol. Chem. Eng. Sci. 47, 3145-3148 (1992)

17. Reverchon, E.: Supercritical antisolvent precipitation of microand nano-particles. J. Supercrit. Fluid 15, 1-21 (1999)

18. Charoenchaitrakool, M., Dehghani, F., Foster, N.R.: Micronization by rapid expansion of supercritical solutions to enhance the dissolution rates of poorly water-soluble pharmaceuticals. Ind. Eng. Chem. Res. 39, 4794-4802 (2000)

19. Turk, M., Hils, P., Helfgen, B., Schaber, K., Martin, H.J., Wahl, M.A.: Micronization of pharmaceutical substances by the rapid expansion of supercritical solutions (RESS): a promising method to improve bioavailability of poorly soluble pharmaceutical agents. J. Supercrit. Fluid 22, 75-84 (2002)

20. Sarkari, M., Brown, J., Chen, X., Swinnea, S., Williams, R.O., Johnston, K.P.: Enhanced drug dissolution using evaporative precipitation into aqueous solution. Int. J. Pharm. 243, 17-31 (2002) 
21. Bilati, U., Allemann, E., Doelker, E.: Development of a nanoprecipitation method intended for the entrapment of hydrophilic drugs into nanoparticles. Eur. J. Pharm. Sci. 24, 67-75 (2005)

22. Hua, J., Johnston, K.P., Williams, R.O.: Spray freezing into liquid (SFL) particle engineering technology to enhance dissolution of poorly water-soluble drugs: organic solvent versus organic/ aqueous co-solvent systems. Eur. J. Pharmacol. Sci. 20, 295-303 (2003)

23. Debuigne, F., Cuisenaire, J., Jeunieau, L., Masereel, B., Nagy, J.B.: Synthesis of nimesulide nanoparticles in the microemulsion epikuron-isopropyl myristate/water/n-butanol (or Isopropanol). J. Colloid Interface Sci. 243, 90-101 (2001)

24. Trotta, M., Gallarate, M., Carlotti, M.E., Morel, S.: Preparation of griseofulvin nanoparticles from water-dilutable microemulsions. Int. J. Pharm. 254, 235-242 (2003)

25. Howard, K.S., Nagy, Z.K., Saha, B., Robertson, A.L., Steele, G., Martin, D.A.: Process analytical technology based investigation of the polymorphic transformations during the antisolvent crystallization of sodium benzoate from IPA/Water mixture. Cryst. Growth Des. 9, 3964-3975 (2009)

26. O'Grady, D., Barrett, M., Casey, E., Glennon, B.: The effect of mixing on the metastable zone width and nucleation kinetics in the anti-solvent crystallization of benzoic acid. Chem. Eng. Res. Des. Trans 85, 945-952 (2007)

27. Nagy, Z.K., Fujiwara, M., Braatz, R.D.: Modelling and control of combined cooling and anti-solvent crystallization processes. J. Process Control 18, 856-864 (2008)
28. Overhoff1, K.A., Johnston, K.P., Robert, O., Williams, R.O.: Improvement of dissolution rate of poorly water soluble drugs using a new particle engineering process: spray freezing into liquid, In: Polymeric Drug Delivery II, Chapter 20, pp 305-319. (2006)

29. Jie-Xin, W., Qian-Xia, Z., Yue, Z., Lei, Sh, Jian-Feng, Ch.: Microfluidic synthesis of amorphous cefuroxime axetil nanoparticles with size-dependent and enhanced dissolution rate. Chem. Eng. J. 16, 844-851 (2010)

30. USP-32th edition, NF-27nd edition. In: Azithromycin; United state pharmacopeial convention. 12601, Twinbrook Parkway, Rockville, MD 20852, Vol. 2, pp. 1613-1615. United book press, Maryland (2008)

31. Yuancai, D., Wai Kiong, N., Shoucang, S.H., Sanggu, K.: Preparation and characterization of spironolactone nanoparticles by antisolvent precipitation. Int. J. Pharm. 375, 84-88 (2009)

32. Gandhi, R., Pillai, O., Thilagavathi, R.R., Gopalakrishnan, B., Kaul, C.L., Panchagnula, R.: Characterization of azithromycin hydrates. Eur. J. Pharm. Sci. 16, 175-184 (2002)

33. Choemunng, A., Na-Bangchang, K.: An alternative liquid chromatography-mass spectrometric method for the determination of azithromycin in human plasma and its application to pharmacokinetic study of patients with malaria, Southeast Asian. J. Trop. Med. Public. Health 41, 1048-1058 (2010)

34. Hattori, Y., Haruna, Y., Otsuka, M.: Dissolution process analysis using model-free Noyes-Whitney integral equation. Colloids Surf. B Biointerfaces. 102, 227-231 (2013) 